Vanhooren, S. (2019). Struggling with meaninglessness: A case study from an experiential-existential perspective. Person-centered \& Experiential Psychotherapies. Advance online publication. doi:

10.1080/14779757.2019.1572029

\title{
Struggling with Meaninglessness: A Case Study from an Experiential-Existential Perspective
}

\begin{abstract}
Meaninglessness is one of the biggest threats of our era. Meaninglessness is not only one of the possible symptoms of depression; meaninglessness as such is a complex experience which can be identified at a micro-dimensional felt sensed level, as a meaning gap at a mesodimensional narrative level, and as groundlessness at a macro-dimensional existential level. Person-centered therapies have explicitly focused on the micro- and meso-dimension of meaning; existential therapies have emphasized the macro-dimensions by helping their clients to face the existential givens such as meaninglessness and meaning. In this article we explore how experiential-existential psychotherapy could help clients in dealing with meaninglessness by addressing this experience with micro-, meso-, and macro-dimensional interventions. A case study reveals how all meaning-dimensions are important, but not at any moment. The client concludes the therapy with discovering what is most essential to him in life. From this experience he finds the courage to engage with life at the fullest, whether it is ultimately meaningful or not.
\end{abstract}

Keywords: meaninglessness, meaning, depression, existential guilt, existential, personcentered, focusing, experiential-existential 
Vanhooren, S. (2019). Struggling with meaninglessness: A case study from an experiential-existential perspective. Person-centered \& Experiential Psychotherapies. Advance online publication. doi:

10.1080/14779757.2019.1572029

\section{Introduction}

Thomas, a 64-year old man, was suffering from a profound sense of meaninglessness. Being caught in this state of darkness - and in DSM 5 language a major depressive disorder (American Psychiatric Association, 2013) - he hoped to find a therapist who could help him cope with life's challenges in a different way. Thomas had consulted person-centered and experiential psychotherapists before. He had the feeling, however, that the existential layer of his meaninglessness remained unaddressed during these therapies. Eventually he found someone who practiced experiential-existential psychotherapy; an emerging approach which integrates person-centered, experiential and existential therapeutic practices (Madison, 2010, 2014a, 2014b; Vanhooren, 2018; Vanhooren, Dezutter, \& Leijssen, 2015).

Meaninglessness as such is a complex phenomenon. It has received far less attention in contemporary research compared to the experience of meaning (e.g. Hicks \& Routlegde, 2013; Markman, Proulx, \& Lindberg, 2013; Wong, 2012). In the positive psychology literature, the experience of meaning has been associated with psychological and physical well-being, health, resilience, virtues, and spirituality (Glaw et al., 2017; Roepke, Jayawickreme, \& Riffle, 2014; Steger, 2012). Lower levels of meaning have been associated with psychopathology (Steger, 2012; Volkert et al., 2014). Feelings of meaninglessness have been associated with depression (American Psychiatric Association, 2013). Clients who suffer from depression indeed show lower levels of meaning compared to other clients in the clinical population (Volkert et al., 2014). The fact that depression is taking epidemic proportions and is expected to be the most lethal 'disease' around the globe by 2030 (Lépine \& Briley, 2011) seems to parallel Viktor Frankl's (1959/2006) prediction that we have entered an era of meaninglessness. 
Vanhooren, S. (2019). Struggling with meaninglessness: A case study from an experiential-existential perspective. Person-centered \& Experiential Psychotherapies. Advance online publication. doi:

10.1080/14779757.2019.1572029

Although the number of studies is limited, the good news is that psychotherapy seems to have a positive influence on one's experience of meaning in life (Hill, 2018; Vanhooren et al., 2015; Volkert et al., 2014; Vos, 2016). This meaning acts as a buffer against depression and suicidal ideation (Kleiman \& Beaver, 2013; Marco, Guillén, \& Botella, 2017; Volkert et al., 2014). Although Hill (2018) and Vos (2018) have recently suggested ways to address meaning in respectively psychodynamic and meaning-centered therapy, it is still unclear how meaninglessness and meaning can be met at the most concrete level of the clienttherapist interactions.

Person-centered and experiential scholars have pioneered in clarifying how specific client-therapist interactions can lead to better psychotherapy outcomes (Angus et al., 2014; Elliott, Watson, Goldman, \& Greenberg, 2004; Gendlin, 1996; Rogers 1951, 1961; Sachse \& Elliott, 2002). Early person-centered research discovered that it was the way clients were talking about their problems that predicted therapy outcome (Kirtner \& Cartwright, 1958). Gendlin (1962/1997) elaborated this idea and highlighted the crucial role of the client's bodily felt experience in the discovery of new meaning. New meaning unfolds when clients take their time to symbolize - e.g. give words to - their inner bodily appraisal of their situation. Therapists can help the clients to unfold this new meaning by using focusing (Gendlin, 1978); a concrete set of client-therapist interactions that not only helps clients to understand the meaning of their lived experience, but also shifts this lived experience itself.

Angus and Greenberg (2011) and Greenberg and Pascual-Leone (2001) differentiate this fresh-felt sensed meaning from other sources of meaning such as one's life story and one's self concept. Elliott and colleagues (2004) refer also to cherished beliefs or the assumptions people have about themselves and the world. These types of meanings are different from the felt sensed meaning because they are not necessarily attuned to the 
Vanhooren, S. (2019). Struggling with meaninglessness: A case study from an experiential-existential perspective. Person-centered \& Experiential Psychotherapies. Advance online publication. doi:

10.1080/14779757.2019.1572029

experience of the concrete here-and-now situation. There are personal concepts or patterns that have been constructed based on previous life experiences and also by culture.

Rogers (1951, 1961) describes how an incongruence between what can directly be experienced and how one sees one's self through the lens of the self-concept or life narrative can lead to anxiety or to distortion of the current experience. Angus and Greenberg (2011) describe with meaning markers and meaning tasks how the incongruence between the client's life story and directly felt meaning can be changed for the better.

However, from an existential point of view, there is another realm of meaning. In daseinsanalysis, the previous examples of meaning that are closely connected to the particularities of the individual's life (i.e. ontical meaning) are distinguished from another kind of meaning that transcends the individual's concrete situation (i.e. ontological meaning) - although experienced in the concrete situation (Holzhey-Kunz, 2014; Holzhey-Kunz \& Fazekas, 2012). This kind of meaning touches upon the ultimate concerns of humankind (Frankl 1959/2006; Holzhey-Kunz \& Fazekas, 2012; Leijssen, 2014; van Deurzen \& Adams, 2011; Vanhooren, 2018; Vos, 2016; Yalom, 1980). Different from experiencing meaning in one's life, this is about experiencing meaning or meaninglessness of life. The existential approach states that facing these ultimate concerns or existential givens such as death, responsibility, choice, guilt, loneliness, connectedness, etcetera will lead to an awe-inspired and more authentic way of being in the world (Schneider \& Krug, 2017; Yalom, 1980).

In order to study how these different kinds of meaning are interrelated in therapy and to develop more concrete therapist-client interventions that address all aspects of meaning, I distinguish these meanings here as different meaning dimensions: the micro-dimension (felt sense about the here-and-now inner and interactional experience), the meso-dimension (selfconcept, life narrative, cherished beliefs, world assumptions, and other conceptual meanings), 
Vanhooren, S. (2019). Struggling with meaninglessness: A case study from an experiential-existential perspective. Person-centered \& Experiential Psychotherapies. Advance online publication. doi:

10.1080/14779757.2019.1572029

and the macro-dimension of meaning (ultimate concerns, existential givens, self-transcendent ontological meanings) (Vanhooren, 2018).

The goal of this article is to explore how and when to address meaninglessness on a micro-, meso-, and macro-dimension during psychotherapy. In order to advance our quest, we will use a theory-building case study which might lead to hypotheses to test in future research.

\section{Method}

Theory-building case studies refine, enrich, or modify existing theories by comparing theory with the observations in a particular case (Stiles, 2017). Different than hypothesis-testing studies they don't focus on a singular statement which could be confirmed or rejected; theorybuilding case studies search to compare the theory with the reality of the case and aim to enrich the existing theory. In this theory-building case study, we will focus on meaninglessness, the therapeutic relationship, and on the helpful or hindering aspects of micro-, meso-, and macro-dimensional content and interventions. The background theory is the emerging experiential-existential approach which is deeply rooted in the phenomenological theory of Eugene Gendlin and in other existential theories as well (Madison, 2010, 2014a, 2014b; Vanhooren, 2018). Theoretical reflections will be provided in the case study itself.

The rough data of this case study consist of the recorded therapy sessions, notes of the therapists, and the client's comments. Throughout this article, important key sentences of the client are indicated by quotation marks and pivotal moments in the therapy are illustrated with therapy excerpts. In order to guarantee the clients' anonymity, the pseudonym "Thomas" is used and details concerning the description of the client have been changed. The client 
Vanhooren, S. (2019). Struggling with meaninglessness: A case study from an experiential-existential perspective. Person-centered \& Experiential Psychotherapies. Advance online publication. doi:

10.1080/14779757.2019.1572029

formally agreed to have the article published. He also read and approved the case study; his comments have been included.

This therapy consisted of 18 sessions. The first part of our case-study will deal with the initial sessions (1-3) and includes more background information. In this early stage, Thomas formulated his goal for this therapy, which he described as wishing to have the courage to exist, regardless of what life brings. Thomas experienced the therapeutic relationship as vital for him to keep going on. The second part of therapy (sessions 4-12) was characterized by getting to the core of the client problems. The therapist's interventions were explicitly micro-dimensional in this stage. In the last part of therapy (sessions 13-18), the focus shifted more to a meso- and macro-dimension. Thomas discovered what ultimately mattered to him in life. Interestingly, this discovery gave him the courage to engage with life, regardless of whether life has an ultimate meaning or not.

\section{Want to Exist (sessions 1-3)}

\section{The therapeutic relationship}

Thomas, a 64-year old retired white European man, was the client of the author. He was married with two children who had already left the house. He had a $\mathrm{PhD}$ in social sciences and was an open-minded religious Catholic. He had been in therapy with different personcentered and experiential therapists before. He had the feeling, however, that the existential layers of his problems remained untouched. As a consequence, his core problem had not been addressed properly. His current therapist (the author of this article) was a 44-year old white European clinical psychologist who had a religious Catholic and Jewish background. He had been trained as a person-centered, focusing-oriented, and existential psychotherapist, and had 20 years of psychotherapeutic experience. 
Vanhooren, S. (2019). Struggling with meaninglessness: A case study from an experiential-existential perspective. Person-centered \& Experiential Psychotherapies. Advance online publication. doi:

10.1080/14779757.2019.1572029

Thomas had struggled for years with feelings of meaninglessness, hopelessness, restlessness, feeling out of contact with others, having a hard time concentrating, and suicidal ideation. In fact, the described symptoms met the DSM-5 criteria of a major depressive disorder (American Psychiatric Association, 2013). Thomas didn't take any medication. Throughout his life, he had been avoiding conflicts with people and during the lasts months he felt increasingly isolated.

Recently, both of his parents had died. Although his sense of meaninglessness and depressive symptoms predated this loss, their deaths and his own feelings of getting older pushed him to evaluate the significance of his life. As he said in his first session: "I feel like I wasted my life. I never fully lived. Now I can’t waste my time anymore. I don’t want to hide behind my religious beliefs; I want to face the reality. I want to dare to exist, I want to feel alive!"

This clear therapy goal was a strong source of motivation for Thomas. As Bugental (1999) puts it, helping clients to make explicit their personal ultimate life concern is essential for effective therapy. When this life concern becomes the central goal of therapy, it mobilizes the client's search to understand this concern. Interestingly, connecting the therapy goal to the client's ultimate concern is already a macro-dimensional intervention by itself. It creates the openness to bring the therapy process to an existential level throughout the sessions.

In the case of Thomas, it didn't take a lot of effort to get this life concern explicit. What the therapist did was reminding the client and himself about this macro-dimensional therapy goal at several points during the therapy. For example, in the third session, the therapist summarized: "I have the sense that everything is coming together now. You came to therapy because you wanted to dare to exist. Now you are having dreams about the death of your children; your parents died recently. How are these things connected?" 
Vanhooren, S. (2019). Struggling with meaninglessness: A case study from an experiential-existential perspective. Person-centered \& Experiential Psychotherapies. Advance online publication. doi:

10.1080/14779757.2019.1572029

Research about the therapeutic alliance shows that the consensus about this goalaspect of the therapeutic alliance is a predictor of therapy outcome (Wampold, 2015). The task-aspect - i.e. the consensus on how to reach the goal - was discussed as well. Knowing that the client was religious, the therapist used the biblical metaphor of the exodus of the Israelites who left Egypt. For the client this metaphor was most helpful, because he understood that they would have to wander through the desert of meaninglessness before they would reach a different place, an unknown promised land. In using this metaphor, the therapist connected the therapy task to a meso-dimension (cultural religious meaning) and a macro-dimension (facing the existential given of meaninglessness) which both spoke to the client. In session 3, the client specified what he thought was helpful to reach his therapy goal:

C1: I don't censor what I say here. But I do mind what I'm saying here, or how to use words. Searching for the right words seems to be an important part of what we are doing here.

T1: Can you tell me some more about the importance of finding the right words here?

C2: If we discover the right words, the picture becomes clearer... And not only that. Then I also have the sense that you really understand me and understand what we are talking about.

If the therapy goal is aligned with the client's deepest concern and if the therapist and the client agree on how to get there, then the therapeutic process becomes (a part of) the client's life project and it might instill hope for success. As Thomas puts it in C2, the goal and task of the therapeutic alliance are interrelated to the experience of the affective aspects of the therapeutic relationship. As Thomas verbalized it, he felt "at home" with the therapist; a feeling of connection that he craved for in other relationships. When this experience of feeling 
Vanhooren, S. (2019). Struggling with meaninglessness: A case study from an experiential-existential perspective. Person-centered \& Experiential Psychotherapies. Advance online publication. doi:

10.1080/14779757.2019.1572029

at home was further explored, Thomas explained how he felt deeply understood and accepted by the therapist, and he experienced himself and the therapist as being authentic: a remarkable summary of Rogers' (1961) core conditions of the therapeutic relationship.

When the client read this article, he added that the formulation of the therapy goal and task gave him the feeling that the therapist really understood what he was going through. He also felt deeply understood and cared for when the therapist referred to some existential literature during the first session and throughout the therapy - which can be understood as macro-dimensional interventions.

Contrary to what one might expect, Thomas had a hard time focusing on his bodily experiences during this first stage. Thomas could describe how he was functioning and what he was thinking, but he did not have a direct access to his experiential flow. As a result, he tended to approach his problem from a more intellectual and conceptual meso-dimensional angle.

\section{Meaninglessness as a shared experience}

Considering the therapeutic relationship in all its aspects, the therapy started in the best circumstances. However, Thomas's meaninglessness had its effect on the therapist. From Gendlin's phenomenological point of view, this is not a surprise. Inspired by Husserl's intentionality and Heidegger's dasein (being-in-the-world), Gendlin (1973) argues that being human means that we are constantly in interaction, or more correctly, that we are our interaction. On the one hand, this means that even just the presence of the therapist can make a difference in how the client experiences the world - at least during the therapy. For example, Thomas felt more focused and energized during these early sessions compared to his daily life. On the other hand, this also means that the client's experience influences the therapist's being-in-the-world - again at least during the sessions. This allows the therapist to 
Vanhooren, S. (2019). Struggling with meaninglessness: A case study from an experiential-existential perspective. Person-centered \& Experiential Psychotherapies. Advance online publication. doi:

10.1080/14779757.2019.1572029

resonate with the client's experiences, but it can also have a significant effect on the therapist's existence. During this first stage of therapy, the therapist was on the edge of getting absorbed in a sense of meaninglessness and despair concerning Thomas's therapy.

From the first session, the therapist sensed the heaviness which the client was carrying. In the therapist's experience, it felt as if death and meaninglessness were palpable in the room. Meaninglessness has been described by Tillich (1952/2000) as an experience of non-being; a state that is accompanied by angst and eventually by despair. For Yalom (1980) meaninglessness is an existential given which can't be solved or altered, and the sudden realization of meaninglessness can be compared with an experience of total groundlessness. Camus (1942/1975) describes how one can suddenly be overwhelmed by this groundlessness and realize that life as such is absurd. There are not a lot of options left once people become aware of the absurdity of existence, states Camus: they can try to hide from this reality by keeping one's self busy, or try to face this absurdity with all its consequences.

In the case of Thomas, both the therapist and the client seemed hesitant to directly explore Thomas's meaninglessness. Thomas would later explain that he had been running away from this sense of meaninglessness since his childhood. Although it had always been there, he never really "met" his meaninglessness. The therapist felt concerned for Thomas and was at the same time overwhelmed by the client's meaninglessness. It made Yalom's groundlessness and Tillich's non-being very touchable. As a result of Thomas's resistance and the therapist feeling paralyzed, they didn't go straight to the core but circled around by exploring Thomas's experience of meaninglessness on a meso-dimensional level. They explored how this meaninglessness appeared in the client's relationships.

Thomas became more aware of how he behaved in relation to others. He had a better understanding of who he was with others; he could see how he disappeared in relationships by eliminating his own needs. Between sessions Thomas tried to be more authentic in these 
Vanhooren, S. (2019). Struggling with meaninglessness: A case study from an experiential-existential perspective. Person-centered \& Experiential Psychotherapies. Advance online publication. doi: 10.1080/14779757.2019.1572029

relationships. However, neither Thomas nor the therapist were getting closer to the core of Thomas's basic concerns, and it felt to both as if little progress was being made.

The fact that meaninglessness was not directly addressed slowed the therapeutic process down. The therapist started to worry and to search for ways to make the client - and himself - feel better. Although this was not the usual style of the therapist, he found himself looking for immediate solutions. For example, when the client experienced that the therapeutic relationship felt like "home" in contrast to his other relational experiences, the therapist helped the client to explore how he could help himself to feel more at home with other people too. Although this is not per se wrong, by searching for quick solutions the therapist was colluding with the client's tendency to avoid experiencing meaninglessness in a direct way. As Gendlin (1990, p. 206) warns:

"The essence of working with another person is to be present as a living being...Do not let focusing, or reflecting, or anything else get in between."

The challenge for the client was to contact his bodily felt sense of his meaninglessness; for the therapist it was to help Thomas to get to this micro-dimensional point and, at the same time, to contain these experiences of meaninglessness.

Indeed, as Abeyta and his colleagues (2015) discovered in a series of experimental studies, having an openness towards and clarity about positive and negative feelings helps people to experience their lives as meaningful, even when confronted with existential threat. This reminds us of Kierkegaard's conviction that one's essence becomes clear when one experiences (and doesn't avoid experiencing) despair (Gee, Loewenthal, \& Cayne, 2011). In order to become aware of one's essence, Kierkegaard adds, an inner exploration of one's self is indispensable (Scholtens, 1978). 
Vanhooren, S. (2019). Struggling with meaninglessness: A case study from an experiential-existential perspective. Person-centered \& Experiential Psychotherapies. Advance online publication. doi:

10.1080/14779757.2019.1572029

The tide changed when Thomas told the therapist in session 4 about the nightmares he had during the last week. He dreamed about his daughter's funeral; Thomas felt himself crying "like an animal." He also had a dream about a suicidal attempt of his other daughter.

\section{Meaninglessness and Rebellion (sessions 4-12)}

\section{Despair and reanimation}

In this nightmare, Thomas found himself talking to his daughter who explained to him that she could not bear her life anymore. Her life felt totally meaningless and she was suffering without perspective. She said she wanted to finish her life. In his dream, Thomas was listening patiently to his daughter and acknowledged her wish to be dead. He could really comprehend her death wish. However, when he discovered that she disappeared after this conversation to her bedroom and stayed away for more than an hour, he started to panic. He had to force her door and found her lying on the floor with an overdose of drugs. He took her to the hospital where she was saved.

In session 4, the dream gave the therapist the opportunity to help the client experience his core theme. As Gendlin (1996) states, it is not by talking about a subject but by experiencing one's concern on a bodily felt level that makes change or growth possible. By welcoming every aspect of this felt sense and searching for the words or symbols that express the whole of this felt sense, the issue itself starts to shift as its meaning becomes clear (Gendlin, 1996). Interestingly, it is on this crossroad of preverbal awareness and symbolizing that new meaning arises. From Gendlin's perspective (1973), we experience in this embodied felt sense our here-and-now interaction with the world in the most authentic and direct way. Entering this micro-dimension gives us access to our existence or - as it is happening in the here-an-now - to our 'existing'. Dream images are symbolizations of our felt sense (Gendlin, 
Vanhooren, S. (2019). Struggling with meaninglessness: A case study from an experiential-existential perspective. Person-centered \& Experiential Psychotherapies. Advance online publication. doi:

10.1080/14779757.2019.1572029

1986) and experiencing the felt sense of these images can bring us to what is crucial in our lives.

Thomas's dream was rooted in a real experience with one of his children many years ago. Nonetheless he was surprised by how he stayed so calm in his dream while listening to the death wish of his daughter. In the second part of the dream, after empathizing with this daughter's suicidal thoughts, he acted contrary and saved her from committing suicide. The therapist recognized this double tendency in Thomas: "There is something in you that deeply recognizes the heaviness and meaninglessness of life, but there also seems to be something in you that, regardless of that heaviness, says to your daughter: 'You have to stay alive.' You force the door. You bring her to the hospital. What is that, that seems to rebel, takes action, while you experience life as a burden?" Although Thomas can't respond immediately, he recognizes this double tendency:

C1: Yes, now that I'm thinking about it, there is something that wants to live and feel. It is noticeable in that wish, that urge to move, to run, to swim, to feel that you have a body... Maybe this is something different, but I became aware this week that I feel irritated faster than usual and that I don't seem to hide this. I also notice the opposite... Last week we went to a concert; the Magnificat of Bach... I really felt touched, I almost could cry - but I can't cry. That joyfulness. I felt my mind opening when I heared the sentence "He has seen me."

T1: More easily irritated... You feel more easily touched, both in a negative and in a positive way... Something is opening up. What does that do to you?

C2: At the moment that gives me energy, and that makes me happy. During the week I really felt burdened by a total lack of energy and hopelessness...

T2: Talking here gives you energy... 
Vanhooren, S. (2019). Struggling with meaninglessness: A case study from an experiential-existential perspective. Person-centered \& Experiential Psychotherapies. Advance online publication. doi:

C3: Yes!

T3: So where do you feel, where do you notice this "this makes me happy?" Where do you feel that energy in your body?

C4: Maybe that's feeling more breath...

T4: And where do you feel that hopelessness?

C5: That's a shrinking...

T5: That's a shrinking movement.

C6: Yes, that feeling of breathlessness. Feeling like doing nothing. The things that have to be done, they are heavy, pounds, pounds...

T6: You say a shrinking, breathlessness, heavy weights ... It makes me think of your dream; the burden of being alive, the meaninglessness of life, and then feeling reanimated here, getting new energy...

Although Thomas starts to get more in touch with his feelings (C1) and to address his bodily felt experiences (C4, C5, C6), he still keeps some distance. Instead of attending his felt sense fully, he symbolizes his felt sense with "maybe" (C4) without checking if this fully matches his bodily felt sense. The therapist does not let Thomas check any further, because he senses that Thomas's capacity to attend this bodily experience might be reached at this point. Instead, the therapist takes a different track and helps the client to localize and verbalize that other part of the dream: his meaninglessness. The therapist picks up on both tendencies, the meaninglessness and something that wants to be alive. In the same session this reminds him of the macro therapeutic goal of the client who wants "to dare to exist". Instead of using interventions that would encourage the exploration of the meso-dimension of meaning (for example explore of what it means to be a father), the therapist steers the session into a micro- 
Vanhooren, S. (2019). Struggling with meaninglessness: A case study from an experiential-existential perspective. Person-centered \& Experiential Psychotherapies. Advance online publication. doi:

10.1080/14779757.2019.1572029

direction using focusing interventions (T3, T5, T6) and interweaves a macro-dimension, pointing at meaninglessness of life (T6).

\section{Heavy blood and rebellious anger}

At the start of session 5, Thomas expresses his wish to explore a heavy feeling which has dominated his whole life. The therapist is eager to do this. Instead of exploring or asking questions about how the client experiences this heavy feeling in contact with people or in his life history (meso-dimension), the therapist helps the client to get in touch with this feeling on a micro-dimension by using focusing, which almost takes the entire session.

C1: That feeling of being down has been strong the last week. And I don't understand it. I don't have any grip on it. I only know it as something that has been there my entire life. A force that sucks me down, pulls me down...

T1:Mh...

C2: That sounds pretty vague, I know...

T2: So, do you sense this experience at this very moment?

It is remarkable that Thomas brings a rich experiential description in $\mathrm{C} 1$. At the beginning of this session, he is already closer to his bodily felt sense than in the last session. The image of something that sucks or pulls himself down refers to a bodily movement, a symbolization of the felt sense of his meaninglessness. The therapist notices that the client's description is experientially rich and the therapist can also sense this feeling in the space between them (T2). In between the sessions, the therapist has been questioning himself on his own urge to 'solve' the heaviness in the room and, being aware of it, he chooses on the spot to 
Vanhooren, S. (2019). Struggling with meaninglessness: A case study from an experiential-existential perspective. Person-centered \& Experiential Psychotherapies. Advance online publication. doi:

10.1080/14779757.2019.1572029

help the client to 'be' with this experience. In doing so, he takes a leap of faith and hopes - as Gendlin (1996) argues - that by staying with this felt sense something else will emerge.

Thomas further describes his felt sense as having "heavy blood that has a dark quality." He shares that his sister also suffers from having the same heaviness. The therapist, however, does not take the meso-road to explore this relationship or history, but helps the client stay with this experience in the here-and-now. After attending this experience for more than half an hour and trying to describe how it feels, Thomas can allow himself to fully experience this felt sense and to acknowledge how something in himself is surrendering to this fatalism and despair. Interestingly, this allows him also to experience a counter-weight $(\mathrm{C} 4, \mathrm{C} 5)$ :

T3: So you experience this heavy blood as something black, tiring, and it feels like lead.

C3: Yes, and..., and... There is that thing and... Fatalism is a strange word...Yes, surrendering as if, surrendering because there is no energy, there is no energy to counter it.

T4: Yes...

C4: [Silence]. And on the other hand, there is the... Yes. On the one hand there is the despair and on the other hand, the, the, anger. Maybe yes. While I have not been angry in years... Not at another person now but at myself. At myself, man... You won't have lived!

T5: There is something that starts to worry? And is angry.

C5: That's in a way, I can curse myself, man, what, what are you doing here? That's not being alive! That's waiting until it's over! Until the light goes out! 
Vanhooren, S. (2019). Struggling with meaninglessness: A case study from an experiential-existential perspective. Person-centered \& Experiential Psychotherapies. Advance online publication. doi:

10.1080/14779757.2019.1572029

T6: Yeah. So there is something in you which feels like dark blood, that sucks you down, that sucks your energy away, that feels like lead, that takes your courage away... But there is another part that says: "Hey you there! You won't have lived!"

Thomas further identifies this angry part as something that revolts or rebels against that massive dark blood of despair. He recognizes this rebelliousness when he goes running or swimming. At the same time, his rebelling has kept him away from fully experiencing this black despair, because there is the anxiety to be absorbed in this heavy meaninglessness and to surrender - just like his daughter in that dream - to death. From a person-centered point of view, it takes a strong therapeutic relationship to look into dark and frightening experiences (Angus \& Greenberg, 2011). Gendlin (1996) calls experiences that seem to be stuck "frozen wholes." The only way to bring them back into process is to attend these frozen wholes and reside with them. Once one has experienced the full felt sense and has symbolized the felt meaning of this experience (T3, C3), the process goes on and the experience shifts $(\mathrm{C} 4, \mathrm{C} 5)$. The therapist helps the client later in this session to ask this darkness what it really needs. The client answers that the dark blood needs attention. When the therapist asks Thomas how he could give this dark blood attention, the client answers that he could ask this heavy blood this particular question: "Is it allowed to help you", referring to an experience he had when he fell from a cliff and an alpinist asked him this very question. Interestingly, the experience shifts now from a micro to a meso-dimension; this meso-dimension, however, seems to have a different quality, being closer to the client's actual experience. It is not a way to hide from the actual experience.

From an existential perspective, we see in this session almost an in vivo description of Tillich's book The Courage to Be, or Kierkegaard's search for the essential. In facing darkness, something different appears, something that calls to be alive. However, Thomas 
Vanhooren, S. (2019). Struggling with meaninglessness: A case study from an experiential-existential perspective. Person-centered \& Experiential Psychotherapies. Advance online publication. doi:

10.1080/14779757.2019.1572029

needed another person who was willing to enter this darkness together with him; someone who could sense it, without running away from it or being destroyed by it. As Thomas noticed afterwards, in this fifth session, he came to the core of his problem.

In the next sessions, micro-dimensional interventions were the most prevalent, with focusing more on the bodily felt sense, interwoven with attention for the existential macrolevel in the shape of meaninglessness, the experience of existential guilt ("you won't have lived", C4, C5), and something that wants to live an authentic life. Session 5 had an immediate effect. The client watched himself standing up for himself, which surprised him. These experiences of standing up for himself were micro-dimensionally explored in the next session.

\section{The vague powers}

Just as in the previous session, the therapist helped Thomas in session 6 to attend the embodied felt senses that were linked to these new acts of standing up for himself. Thomas experienced a felt sense around his chest, which he could symbolize as transcending his drift sand and even transcending time. He felt strong and "fully alive" and described it further as a revolt "against vague powers".

Step by step it became clear that both poles he had been describing since he had this dream - the heavy meaninglessness, despair, heavy blood versus the rebellious side that wanted to be alive - were closely linked to his difficult relationship with his father. Not being aware of the link between these two dynamics and this relationship, Thomas told the therapist that he never rebelled against his father, which he deeply regretted right now. The therapist asked Thomas how it would be to talk to his father - who died a couple of months ago - in this session. The therapist tried to bring Thomas's experience of his father in the here-andnow by inviting Thomas to do some empty chair work for unfinished business, a method 
Vanhooren, S. (2019). Struggling with meaninglessness: A case study from an experiential-existential perspective. Person-centered \& Experiential Psychotherapies. Advance online publication. doi:

10.1080/14779757.2019.1572029

elaborated in gestalt therapy (Brownell, 2016) and emotion-focused therapy (Elliott et al., 2004).

The therapist had several reasons for inviting Thomas to have this kind of here-andnow conversation with his father. First, he wanted to prevent Thomas from exploring this relationship only on a conceptual narrative meso-dimension; this kind of exploration had not been so fruitful during the first sessions. Second, by bringing his father to this empty chair, his experiential interaction with this significant person would become a bodily felt experience with the possibility of unfolding its full meaning. Third, if Thomas was able to speak to his father, this might offer a corrective experience by itself, giving Thomas the chance to resist his father and other "vague powers" and to feel alive.

However, in session 6, the empty chair work was only partially successful. It was interesting to notice how Thomas started to have the same felt sense of having heavy dark blood as soon as the image of his father appeared. Talking to his father from face-to-face was too challenging at this point. Thomas had vivid memories of the many times he tried to talk to his father by writing him letters and cards which always remained unanswered. Although he could not face his father while imaging him in this empty chair, it became clear how his father had dominated his life. As Thomas said: "My father had a tremendous influence on all my life decisions."

\section{Life is good}

After session 7, which was marked by micro-dimensional interventions such as focusing on Thomas's experience of "feeling death already residing in my body," Thomas opened session 8 by remarking that he had the feeling that he didn't see the full picture yet. Something was still missing. He also mentioned that he would have his $65^{\text {th }}$ birthday very soon which he felt as a chance to make a new start. For unclear reasons, Thomas felt like he 
Vanhooren, S. (2019). Struggling with meaninglessness: A case study from an experiential-existential perspective. Person-centered \& Experiential Psychotherapies. Advance online publication. doi:

10.1080/14779757.2019.1572029

had to visit the graves of his parents first. He wanted to tell them some things, and by reflecting on what he might possibly say, it became clear to him that his parents wouldn't have much to offer for his future. The therapist invited Thomas to use this session as a preparation to meet his parents at the graveyard. In a long empty chair dialogue, Thomas found this time the courage to stand up against his father. The therapist and Thomas took their time to visualize his father and mother in the room, with his father sitting in his old chair and making some silly remarks about the dangerous staircases. The therapist invited Thomas to switch chairs and to sit in his father's chair, in which Thomas could experience how his father had huge expectations of him which departed from his own missed opportunities and frustrations. However, with his son not meeting his expectations, his father felt deeply disappointed and angry because Thomas would have wasted his talents. In this chair dialogue Thomas confronted his father. Thomas was able to find his voice against his father and mother, while his gestures (clapping hands, kicking the floor) made clear that he was not playing a role. The fact that he could speak out loud what he never had dared to say or even think before, had a remarkable effect.

Thomas visited the graveyard a couple of days later and celebrated his birthday with his wife and children. He never felt so connected to them before. During the same week he also visited an old friend which felt remarkably relaxing. To his own surprise, life felt good. He was not burdened with a sense of meaninglessness; he just felt connected to his family and friends. He was embracing life.

However, two sessions later - therapy is not a straightforward process - a counterattack from within swept this good feeling away. With an unseen strength, Thomas humiliated himself, calling himself an ugly chicken. No matter what the therapist tried, Thomas could not, or did not want to, take a little distance and look at what was happening in this conversation. It was only one session later that he could identify the bullyragging voice of his 
Vanhooren, S. (2019). Struggling with meaninglessness: A case study from an experiential-existential perspective. Person-centered \& Experiential Psychotherapies. Advance online publication. doi: 10.1080/14779757.2019.1572029

father inside himself. In fact, he was so impressed by the destructive power of this voice that he took distance from it.

In the middle section of this therapy (session 4-12) Thomas and the therapist had worked hard on this micro-dimensional level. Thomas managed slowly and steadily to contact his dark feelings, which he deeply feared. In symbolizing his felt sense, new elements completed the picture, revealing the full meaning of his experience of meaninglessness. Interestingly, by attending this felt sense - as could be predicted by Gendlin's theory (1996) his inner process shifted and a different attitude towards life appeared, one of standing up for himself. This seed of courage to engage with life would become more visible in the last part of the therapy. As we will see, the emphasis of the next sessions shifted to a meso- and macro-dimension with less micro-dimensional interventions. However, the micro-dimensional sessions had an important influence on the way Thomas was engaging with this meso- and macro-content. As Rogers (1961) and Gendlin (1996) describe, it is by working on this felt sense level that clients acquire an increasing openness to experience, which results in a different way of relating to one's self and to others. In Buber's (1923/2003) and Cooper's (2015) words, there is a shift from an object-like I-It (towards the other) and I-Me (towards one's self) relationship to a personal I-Thou (towards the other) and I-I (towards one's self) relationship.

By repeatedly working on this felt sense level, the client learns how to contact and how to be open to his existence (Leijssen, 2007). He also develops a vast I-I relationship. It is probably this changed inner relationship which made meso- and macro-dimensional interventions in the next stage fruitful. 
Vanhooren, S. (2019). Struggling with meaninglessness: A case study from an experiential-existential perspective. Person-centered \& Experiential Psychotherapies. Advance online publication. doi:

10.1080/14779757.2019.1572029

The Essence of Living (sessions 12-18)

One of the main subjects of the next sessions was his unfinished life projects. Thomas had the feeling that these unfinished projects were feeding his frustration and his experience of meaninglessness. One of these projects was about turning his dissertation into a book. Due to a dispute with his supervisor this never happened. Freed from battles with "vague powers" Thomas was taking on this challenge again. He was rethinking the subject of his dissertation and gave himself a deadline to do something with it. At the same time, Thomas took steps to “own" his art sculptures which were namelessly on display in the city. These were important steps on a macro-dimension, taking ownership and responsibility over his life.

On a meso-level, Thomas reflected on the life of his parents. In session 13, the therapist noticed how different Thomas's values were compared to his siblings and parents. This meso-reflection was surprising to Thomas. In talking to his wife about this difference which she also thought about but never mentioned - he experienced a new kind of liberation and joy, experiencing himself being different and unique which shifted his life narrative and self-concept.

As life is unpredictable, an unknown cousin suddenly showed up in Thomas's life. Between session 14 and 15, Thomas sent an e-mail to the therapist in which he explained the story in order - Thomas's words - not to lose time in telling the story itself during the session so there would be more time to digest it during the session. In short, the story goes that his grandfather was engaged to a French lady. However, the French fiancée broke up with his grandfather - although being pregnant from him. The grandfather was not allowed by her to visit his French son, but he sent him letters and postcards. The grandfather's heartiness towards the son he never met - and which he kept a secret from his new Belgian fiancée was in huge contrast to the emotional distance between him and his children. When the 
Vanhooren, S. (2019). Struggling with meaninglessness: A case study from an experiential-existential perspective. Person-centered \& Experiential Psychotherapies. Advance online publication. doi:

10.1080/14779757.2019.1572029

grandfather became old and disabled, he was taken in Thomas's parental house. Thomas painfully remembered how his grandfather was maltreated by his parents. In session 15 Thomas took his time to talk about this cruel story, pouring his heart out, cried, and unleashed his anger towards his parents for the maltreatment of his grandfather who wasn't even properly buried. Thomas felt also guilty not having done more for his grandfather, although he was at that time only a child.

While Thomas was venting his anger, the therapist - inspired by what was happening in the session - asked him a question that brought the whole therapy straight to the core:

T1: So Thomas, what's expected from you now?

C1: That means being there for my children, being there for my wife... [silence]. Taking care of my relationship with my siblings...; regardless of what I think of them...

T2: It shows you Thomas what really matters to you... Or one of the things that matter to you.

C2: [Silence and sigh]... It's the only thing that matters... [in a quiet voice]. It's the only thing... It's the only thing...

T3: How does it feel to speak these words Thomas?

C3: I'm getting emotional, yes... [There is uncertainty in his voice].

T4: It's the only thing...

C4: It's the only thing... In the end it's also the only desire a person has. Connection. And all the rest... That book that I'm working on... But in fact... It has its relative value... But actually...

T5: Actually... 
Vanhooren, S. (2019). Struggling with meaninglessness: A case study from an experiential-existential perspective. Person-centered \& Experiential Psychotherapies. Advance online publication. doi:

10.1080/14779757.2019.1572029

C5: If you can be there for some people... Being more attentive towards others..., visiting the people that I'm reluctant to visit...

T6: It has become clear and distinct: that's what is important in the end. No less and no more.

C6: No less and no more.

T7: And that's my purpose in life?

C7: The only... [silence]. Thinking about religion; whether I die as a religious person or as an atheist... that doesn't matter... That doesn't matter! But being a father, being a husband, being a friend, ...

T8: Being yourself...

C8: Being yourself... emerges by being with the other... That's the only thing that matters.

In the following session, which was 3 weeks after session 15, Thomas reports how he invested time in visiting people and being more attentive towards others. He repeats his embodied conviction that the ultimate meaning is about connection and being there for the other. It is remarkable how Thomas speaks these words with clarity, strength, and energy. At the same time, he acknowledges that this does not take away the question of whether life is meaningful or not. But what he has discovered is a solid foundation for facing a possible existential meaninglessness. For Thomas, it does not feel like he has to hide from the existential reality with its givens. He has found his courage to live.

Interestingly, the therapist shifted intuitively in these last sessions to meso- and macrodimensional reflections and questions. Thomas, having been soaked in a microphenomenological bath, can be open to his inner flow of experiences. Because of this change, 
Vanhooren, S. (2019). Struggling with meaninglessness: A case study from an experiential-existential perspective. Person-centered \& Experiential Psychotherapies. Advance online publication. doi:

10.1080/14779757.2019.1572029

the therapist does not need to intervene on this micro-dimensional level. Instead there is more space to explore the meso- and macro-dimension of his life.

In fact, intervening on a micro-dimensional level could even disrupt the process at this point. In the excerpt, the therapist (T1) asks a macro-dimensional question about Thomas's purpose in life, seizing the client's power of the experienced disgust towards his grandfather's maltreatment. Thomas $(\mathrm{C} 1, \mathrm{C} 2)$ is able to see clearly what matters to him in the end. The therapist slips away by asking Thomas to answer a question which might refer more to a micro-dimension (T3). Thomas answers, but it seems to lead him away from his track (he answers with an uncertain or doubting voice). The therapist notices this and brings Thomas back to the macro-dimension where the shift is happening (T4) and where Thomas picks it up (C4).

\section{Discussion and conclusion}

The purpose of this theory-building case study was to explore how we can work with meaninglessness and how micro-, meso-, and macro-dimensional interventions could contribute.

In general, the case of Thomas can be understood as a paradoxical endeavor to search for the meaning of the client's meaninglessness. Thomas started his therapy with a deep sense of having led a meaningless life. This meaninglessness was originally experienced in his sense of restlessness, hopelessness, and a lack of energy (micro-dimension), the feeling that his life had been a failure (meso-dimension), and in the increasing awareness that life as such might be meaningless (macro-dimension). The therapeutic process was marked by a therapeutic relationship which was significant and meaningful for Thomas and the therapist. In fact, we could say that the relationship itself made a first shift in Thomas' lived experience. 
Vanhooren, S. (2019). Struggling with meaninglessness: A case study from an experiential-existential perspective. Person-centered \& Experiential Psychotherapies. Advance online publication. doi:

10.1080/14779757.2019.1572029

His level of energy was higher during the sessions compared to daily life, he felt more focused instead of being distracted at home and he experienced a spark of hope. The therapeutic relationship also functioned as a safe haven from where Thomas was able to explore his darkness.

At the micro-dimension, Thomas did not initially have easy access to his bodily felt experiences, which reflects an overregulation of his emotional world. He was aware of bodily sensations, such as his lack of energy and restlessness, but had a harder time symbolizing them. Thomas also didn’t link his bodily sensations with circumstances or his life story. Angus and Greenberg (2011) speak of un-storied emotions which they identify as a problem marker for meaning. The fact that his restlessness was not linked to anything could refer to a meaning gap at this meso-dimension. The story of how his father treated him and how his grandfather had been treated was not expressed; as a result, the link between his bodily felt senses and these stories was not made yet. What was clear though was his meaninglessness on a macro-dimensional level. From the first session Thomas addressed this realm and wanted to face the ultimate concern of meaninglessness. For him, his conceptual (meso-dimensional) religious answers no longer sufficed, and he could not experience nor see any meaning or purpose that would give his existence significance.

On an intervention level, interventions on micro-, meso-, and macro-dimensions all contributed to the outcome. However, they were not helpful at all times. The therapy took a good start with formulating the therapy goal and task on a macro-dimensional level ("I want to dare to exist, regardless of what comes") and feeling understood on this macro-dimension. However, the client and therapist lingered at a meso-dimensional level, exploring who Thomas was in relationship to others. Maybe this was helpful to some degree in order to establish safety, but it was clearly not sufficient. Interestingly the meaninglessness itself affected the therapeutic relationship. It took the therapist Kierkegaard's leap of faith to 
Vanhooren, S. (2019). Struggling with meaninglessness: A case study from an experiential-existential perspective. Person-centered \& Experiential Psychotherapies. Advance online publication. doi:

10.1080/14779757.2019.1572029

explore this meaninglessness at a micro-dimension. From an experiential point of view,

Thomas's meaninglessness could be understood as a frozen whole or a structure-bound experience; a stuck way of experiencing the world which repeats itself. Gendlin (1996) explains that it is only by experiencing this structure-bound experience at a bodily experiential level that something might start to shift.

In this case it was crucial to experience this meaninglessness at the fullest, to symbolize the bodily felt sense of this meaninglessness, and to give the same attention to something showing itself (rebellious part) once the felt meaning of this meaninglessness (the "heavy dark blood") was fully experienced and symbolized. Both the rebellious anger ("you won't have lived") and the meaninglessness were further developed in the empty chair dialogue with his parents. In this dialogue and in the meso-dimensional interventions in the last stage of therapy, denied parts of Thomas life narrative were revealed. By being more in touch with the micro- and meso-dimensional meaning of his meaninglessness, macrointerventions (“So Thomas, where does this leave you?”) became very powerful. They helped Thomas to see and experience his ultimate essence in life; regardless of the fact that life might be meaningful or not on an existential level. The discovery of his macro-dimensional meaning ("connection is the only thing that matters") gave him energy and the power to make decisions.

One interesting observation in this case study is that Thomas only started to feel fully energized - not only during the therapy but also in his daily life - once this macrodimensional meaning was revealed. At that moment much work had already been done. In fact, this macro-dimensional meaning was a bodily felt meaning that was also connected to an important part of his life story. It seems like Thomas might have not come to this macromeaning if he didn't develop a way to attend his felt meaning at a micro-dimension in the first place. However, Thomas's "connection is the only thing that matters" reflects a macro- 
Vanhooren, S. (2019). Struggling with meaninglessness: A case study from an experiential-existential perspective. Person-centered \& Experiential Psychotherapies. Advance online publication. doi:

10.1080/14779757.2019.1572029

dimensional revelation because it stretched far beyond his individuality. It was a new and freshly sensed meaning which had been unfolding throughout the entire therapy process.

The experience of this macro-meaning was itself a moment of change. Gendlin (1996) describes how the unfolding of meaning - the right symbolization of the felt sense - is accompanied by a felt physical shift. The experience of meaning is an experiential change. Perhaps this is also the case for the experience of meaning at the other dimensions as well. In fact, when we experience the full meaning of who we are in relation to what transcends us, differences between dimensions of meaning don't make sense anymore. Kirk Schneider expresses this idea by saying that meaning is a sense of awe, discovery, whole-bodied openness to the mystery of simple being (Vos et al., 2017).

The case study itself shows how the three meaning dimensions are intertwined and affect each other. As Greenberg and Pascual-Léone (2001) describe, shifts on an experiential level can influence meaning on a more conceptual level. Leijssen (2007) states that a repeated contacting of one's bodily felt experience broadens one's receptivity for the existential dimension. It is important to remember that therapy is not a matter of searching for meaning on these three levels separately, like checking a list. However, the case study showed that the differentiation between the dimensions helped us to understand the case in a better way. Knowing more about micro-, meso-, and macro-dimensional interventions might, therefore, optimize our person-centered, experiential, and existential approaches. Research is clearly needed to know when and how to use different micro-, meso-, and macro-dimensional interventions.

One remaining question is whether Thomas's therapy would have been different if the therapist was only an existential, a person-centered, emotion-focused or focusing-oriented therapist. The client himself argues it would have been different. His previous experiences with person-centered and experiential therapist left him unsatisfied. In his experience, 
Vanhooren, S. (2019). Struggling with meaninglessness: A case study from an experiential-existential perspective. Person-centered \& Experiential Psychotherapies. Advance online publication. doi: 10.1080/14779757.2019.1572029

something essential had been left out. The existential realm had been bypassed by only focusing on the experiential bodily level, his feelings, or on the story. In his comments on this article, he remarks that the therapist's macro-dimensional and existential view was also noticeable in his use of metaphors, in the fact that he encouraged the client to read essays on choice and meaning, and in his support of the client to take on his unfinished life projects. The client's comments confirm that an experiential-existential approach could be one of the answers to the challenges of our time, where Viktor Frankl's (1959/2006) existential vacuum - i.e. meaninglessness - might take unprecedented levels. 
Vanhooren, S. (2019). Struggling with meaninglessness: A case study from an experiential-existential perspective. Person-centered \& Experiential Psychotherapies. Advance online publication. doi:

10.1080/14779757.2019.1572029

\section{References}

Abeyta, A. A., Routlegde, C., Juhl, J., \& Robinson, M. D. (2015). Finding meaning through emotional understanding: Emotional clarity predicts meaning in life and adjustment to existential threat. Motivation and Emotion, 39, 973-983. doi: 10.1007/s11031-015$9500-3$

Angus, L. E., \& Greenberg, L. S. (2011). Working with narrative in emotion-focused therapy: Changing stories, healing lives. Washington, DC: American Psychological Association.

Angus, L. E., Watson, J. C., Elliott, R., Schneider, K., \& Timulak, L. (2014). Humanistic psychotherapy research 1990-2015: From methodological innovation to evidencesupported treatment outcomes and beyond. Psychotherapy Research, Advance online publication. doi: 10.1080/10503307.2014.989290

American Psychiatric Association (2013). Diagnostic and statistical manual of mental disorders $\left(5^{\text {th }}\right.$ ed). Arlington: American Psychiatric Publishing.

Brownell, P. (2016). Contemporary gestalt therapy. In D. J. Cain, K. Keenan, \& S. Rubin (Eds.), Humanistic psychotherapies: Handbook of research and practice. Second edition (pp. 219-250). Washington, DC: American Psychological Association.

Buber, M. (1923/2003). Ik en Jij [I and Thou]. Utrecht, the Netherlands: Bijleveld.

Bugental, J. F. T. (1999). Psychotherapy isn't what you think. Phoenix, AZ: Zeig, Tucker.

Camus, A. (1942/1975). De mythe van Sisyfus [The myth of Sisyphus]. Amsterdam, NL: De Bezige Bij.

Cooper, M. (2015). Existential psychotherapy and counseling: Contributions to a pluralistic practice. London, UK: Sage publications. 
Vanhooren, S. (2019). Struggling with meaninglessness: A case study from an experiential-existential perspective. Person-centered \& Experiential Psychotherapies. Advance online publication. doi: 10.1080/14779757.2019.1572029

Deurzen van, E. \& Adams, M. (2011). Skills in existential counselling and psychotherapy. London, UK: Sage.

Elliott, R., Watson, J. C., Goldman, R. N., \& Greenberg, L. S. (2004). Learning emotionfocused therapy: The process-experiential approach to change. Washington, DC: American Psychological Association.

Frankl, V. E. (1959/2006). Man's search for meaning. Boston, MS: Beacon Press.

Gee, J., Loewenthal, D., \& Cayne, J. (2011). Therapeutics of despair in the prison setting. European Journal of Psychotherapy \& Counselling, 13, 317-334. doi: $10.1080 / 13642537.2011 .625201$

Gendlin, E. T. (1962/1997). Experiencing and the creation of meaning: A philosophical and psychological approach of the subjective. Evanston, Il: Northwestern University Press.

Gendlin, E. T. (1973). Experiential psychotherapy. In R. Corsini (Ed.), Current psychotherapies (pp. 317-352). Itasca, IL: Peacock.

Gendlin, E. T. (1978). Focusing. New York, NY: Everest House Publishers.

Gendlin, E. T. (1986). Let your body interpret your dreams. Wilmette, IL: Chiron publications.

Gendlin, E. T. (1990). The small steps of the therapy process: How they come and how they help them come. In G. Lietaer, J. Rombouts, \& R. Van Balen (Eds.), Client-centered and experiential psychotherapy in the nineties (pp. 205-224). Leuven, B: Leuven University Press.

Gendlin, E. T. (1996). Focusing-oriented psychotherapy. New York, NY: The Guilford press. Glaw, X., Kable, A., Hazelton, M., \& Inder, K. (2017). Meaning in life and meaning in life in mental health care: An integrative literature review. Issues in Mental Health Nursing, 38, 243-252. doi: 10.1080/01612840.2016.1253804

Greenberg, L. S., \& Pascual-Leone, J. (2001). A dialectical constructivist view of the creation 
Vanhooren, S. (2019). Struggling with meaninglessness: A case study from an experiential-existential perspective. Person-centered \& Experiential Psychotherapies. Advance online publication. doi:

10.1080/14779757.2019.1572029

of personal meaning. Journal of Constructivist Psychology, 14, 165-186. doi:

$10.1080 / 10720530125970$

Hicks, J. A., \& Routlegde, C. (2013). The experience of meaning in life: Classical perspectives, emerging themes, and controversies. Dortrecht, N: Springer.

Hill, C. E. (2018). Meaning in life: A therapists guide. Washington, DC: American Psychological Association.

Holzhey-Kunz, A. (2014). Daseinsanalysis. London, UK: Free Association Books.

Holzhey-Kunz, A., \& Fazekas, T. (2012). Daseinsanalysis: A dialogue. In L. Barnett \& G. Madison (Eds.), Existential therapy: Legacy, vibrancy, and dialogue (pp. 35-51). London, UK: Routledge.

Kirtner, W. L. \& Cartwright, D. S. (1958). Success and failure in client-centered therapy as a function of initial in-therapy behavior. Journal of consulting Psychology, 22, 329-333.

Kleiman, E. M. \& Beaver, J. K. (2013). A meaningful life is worth living: Meaning in life as a suicide resiliency factor. Psychiatry research, 210, 934-939. doi: 10.1016/j.psychres.2013.08.002

Leijssen, M. (2007). Making space for the inner guide. American Journal of Psychotherapy, $61,255-270$.

Leijssen, M. (2014). Existential well-being counselling. In G. Madison (Ed.), Emerging practice in focusing-oriented psychotherapy: Innovative theory and applications (pp. 138-153). London, GB: Jessica Kingsley Publishers.

Lépine, J.-P., \& Briley, M. (2011). The increasing burden of depression. Neuropsychiatric Disease and Treatment, 7, 3-7. doi: 10.2147/NDT.S19617

Madison, G. (2010). Focusing on existence: Five facets of an experiential-existential model. Person-Centered \& Experiential Psychotherapies, 9, 189-204.

Madison, G. (2014a). The palpable in existential counselling psychology. Counselling 
Vanhooren, S. (2019). Struggling with meaninglessness: A case study from an experiential-existential perspective. Person-centered \& Experiential Psychotherapies. Advance online publication. doi:

Psychology Review, 29, 25-33.

Madison, G. (2014b). Exhilarating pessimism: Focusing-oriented existential therapy. In G. Madison (Ed.), Theory and practice of focusing-oriented psychotherapy: Beyond the talking cure (pp. 113-127). London, UK: Jessica Kingsley Publishers.

Marco, J. H., Guillén, V., \& Bottela, C. (2017). The buffer role of meaning in life in hopelessness in women with borderline personality disorders. Psychiatry Research, 247, 120-124. doi: 10.1016/j.psychres.2016.11.011

Markman, K. D., Proulx, T., \& Lindberg, J. (2013). The psychology of meaning. Washington, DC: American psychological Association.

Roepke, A. M., Jayawickreme, E., \& Riffle, O. M. (2014). Meaning and health: A systematic overview. Applied Research Quality Life, 9, 1055-1079. Doi: 10.1007/s11482-0139288-9

Rogers, C. R. (1951). Client-centered therapy. London, GB: Constable.

Rogers, C. R. (1961). On becoming a person. Boston: Houghton Mifflin Company.

Sachse, R., \& Elliott, R. (2002). Process-outcome research on humanistic therapy variables. In D. J. Cain \& J. Seeman (Ed.), Humanistic psychotherapies: Handbook of research and practice (pp. 83-116). Washington, DC: American Psychological Association.

Schneidern K. J., \& Krug, O. T. (2017). Existential-humanistic therapy. Second Edition. Washington, DC: American Psychological Association.

Scholtens, W. R. (1978). Søren Kierkegaard: Wilde ganzen. Dagboeknotities 1846-1855 [Søren Kierkegaard: Wilde geeze. Dairy notes 1846-1855]. Baarn, N: Ten Have.

Steger, M. (2012). Experiencing meaning in life: Optimal functioning at the nexus of wellbeing, psychopathology, and spirituality. In P. T. P. Wong (Ed.), The human quest for meaning: Theories, research, and applications. Second Edition (pp. 165-184).

New York, NY: Routledge. 
Vanhooren, S. (2019). Struggling with meaninglessness: A case study from an experiential-existential perspective. Person-centered \& Experiential Psychotherapies. Advance online publication. doi:

10.1080/14779757.2019.1572029

Stiles, W. B. (2017). Theory-building case studies. In D. Murphy (Ed.), Counselling psychology: A textbook for learning and practice (pp. 439-453). Chichester: WileyBlackwell

Tillich, P. (1952/2000). The courage to be. New Haven: Yale University Press.

Vanhooren, S. (2018). Experiential-existential psychotherapy: Deepening existence, engaging with life. In M. Bazzanu (Ed.), Re-visioning person-centred therapy: The theory and practice of a radical paradigm (pp. 151-163). Abingdon, UK: Routledge.

Vanhooren, S., Dezutter, J., \& Leijssen, M. (2015). Posttraumatic growth during incarceration: A case study from an experiential-existential perspective. Journal of Humanistic Psychology, Advance online publication, 1-24. doi:

$10.1177 / 0022167815621647$

Volkert, J., Schulz, H., Brütt, A. L., \& Andreas, S. (2014). Meaning in life: Relationship to clinical diagnosis and psychotherapy outcome. Journal of Clinical Psychology, 70, 528-535. doi: 10.1002/jclp.22053

Vos, J. (2016). Working with meaning in life in chronic or life-threatening disease: A review of its relevance and the effectiveness of meaning-centred therapies. In P. RussoNetzer, S. E. Schulenberg, \& A. Batthyany (Eds.), Clinical perspectives on meaning: Positive and existential psychotherapy (pp. 171-200). Cham, CH: Springer.

Vos, J. (2018). Meaning in life: An evidence-based handbook for practitioners. London, UK: Palgrave.

Vos, J., Cooper, M., Hill, C. E., Neimeyer, R. A., Schneider, K., \& Wong, P. T. (2017). Five perspectives on the meaning of meaning in the context of clinical practices. Journal of constructivist psychology. Advance online publication,1-15. doi:

$10 / 1080 / 10720537.2017 .1390511$

Wampold, B. E. (2015). How important are the common factors in psychotherapy? An up- 
Vanhooren, S. (2019). Struggling with meaninglessness: A case study from an experiential-existential perspective. Person-centered \& Experiential Psychotherapies. Advance online publication. doi: 10.1080/14779757.2019.1572029

date. World Psychiatry, 14, 270-277.

Wong, P. T. P. (Ed.) (2012). The human quest for meaning: Theories, research, and applications. Second edition. New York, NY: Routledge.

Yalom, I. (1980). Existential psychotherapy. New York, NY: Basic Books. 